\title{
Differential backward masking of words and letters by masks of varying orthographic structure
}

\author{
GLEN A. TAYLOR \\ Texas A\&M University, College Station, Texas 77843 \\ and \\ ROBERT J. CHABOT \\ Kent State University, Kent, Ohio 44242
}

\begin{abstract}
The effects of structural relationships between targets and masks were investigated using a backward-masking paradigm. Specifically, the masking of single letters, common fiveletter words, and five-letter pseudowords masked by a blank flash, strings of overlapped letters, pseudowords, and words was investigated. Target duration was varied from 2 to $32 \mathrm{msec}$, with mask duration held constant at 25 msec. The dependent measure was the critical interstimulus interval for correct target identification. Letters were more effectively masked than words and pseudowords. A blank mask caused the least amount of masking, followed by the overlapped letter strings, and then the word and pseudoword masks. In addition to the overall greater masking effectiveness for the three patterned masks, overlapped letter strings masked letters more effectively than they did words. The implications of current theories of masking for these results and the implications of these results for theories of word recognition were discussed.
\end{abstract}

In 1969, Reicher demonstrated that for brief visual presentations, letters are recognized more accurately when embedded in four-letter words than when presented alone, even when the redundancy advantage for words is controlled. This advantage for words over letters, or "word-letter effect," was obtained when the letters and words were followed by a visual mask. Johnston and McClelland (1973) demonstrated that the word-letter effect depends on the presence of a pattern mask. They replicated Reicher's word-letter effect with a pattern mask, but found performance equivalent for words and letters when the pattern mask was replaced by a contourless masking field. Juola, Leavitt, and Choe (1974) also found equivalent performance for words and letters in the Reicher task when they used a dark postexposure field. The primary question raised by these findings is why different masks differentially favor the recognition of words and letters.

One suggestion as to the source of differential

The authors' contributions to this study were equal; order of authorship is arbitrary. Requests for reprints may be addressed to either of the following: Glen A. Taylor, Department of Psychology, Texas A\&M University, College Station, Texas 77843, or Robert J. Chabot, Department of Psychology, Kent State University, Kent, Ohio 44242. The research was conducted at the University of Kansas and was supported by National Science Foundation Grant BMS74-12801 to James F. Juola. The authors express their deepest appreciation to Jim Juola for his support of them and this research, and for his insightful comments on earlier drafts of this paper. masking derives from an extensive series of studies reported by Turvey (1973). Turvey examined the masking of letters and consonant trigrams by visual noise and pattern masks. He demonstrated that these two types of masks produce essentially different types of masking, and that the locus of the masking effects differs. Letters and trigrams masked by pattern masks underwent what Turvey called "central masking," an interaction at cortical levels similar to what has been termed interruption masking (Kahneman, 1968). Masking by random noise and contourless flashes produced a masking effect in the "peripheral" sensory channel from the retina up to, and perhaps including, primary projection areas of the visual cortex. This masking effect was primarily an integration of the two stimuli similar to luminance summation (Eriksen, 1966). Because the masks usually used in the Reicher (1969) task are similar to Turvey's pattern mask, it might be assumed that the masking effect supporting the wordletter effect is a central masking effect. Contourless masking fields that failed to produce a word-letter effect are similar to the conditions that give rise to peripheral masking. Thus, generalizing from Turvey's findings, it could be suggested that letters alone and letters in words are seen equally well under peripheral masking, but that words evade central masking under conditions in which single letters cannot.

The procedure and theoretical framework developed by Turvey (1973) can be used for interpreting backward 
masking of words and letters by various types of masks. Turvey identified two forms of backward masking, which he distinguished as having different loci. He measured the minimum temporal separation between target offset and mask onset necessary for correct target identification. This interval was called the critical interstimulus interval (CISI) and can be determined by an ascending-limits procedure. Turvey found an inverse relation between target energy and CISI when the target and mask entered via the same visual pathway (binocularly or monocularly) and the mask was either a blank flash or visual noise. These same stimuli produced no masking when they were presented to separate eyes (dichoptic presentation), regardless of energy relationships or interstimulus intervals. Dichoptic masking did occur for letter and trigram targets when the masking stimulus was a pattern of lines the same thickness as the strokes of a letter. This dichoptic pattern masking obeyed a different temporal rule: Onset asynchrony between target and mask necessary for correct target identification was a constant. The masking function for a pattern mask with binocular presentation was a composite of the two masking rules.

Turvey (1973) concluded from his results that there were two masking relations at work, one that operated mainly in the peripheral visual channel when target and mask entered via the same eye, and a second central masking effect that could be found even when the target and mask entered via different eyes. The peripheral masking was multiplicative: Target energy $\times$ CISI $=$ constant, or when luminance was held constant, target duration $X$ CISI $=$ constant. The central masking relation was linear: Target duration + CISI = constant. The relative contribution of each type of masking to an observed masking function is indexed by the magnitude of these linear and multiplicative components.

Whereas generalization from Turvey's (1973) findings to the Reicher (1969) paradigm might seem unwarranted due to differences in procedure and types of stimuli, Jacobson $(1973,1974)$ reported studies that bridge some of these differences. Jacobson (1973, Experiment 2) examined the masking functions for report of words when masked by four types of masks: visual noise, randomly selected letter strings, words unassociated with the target, and words associated with the target. He found unassociated words and random letter strings to be the most effective masks. Significantly less effective were associated words, and least effective was visual noise. Pursuing these results, Jacobson (1974) added two more types of masks to a replication of the earlier experiment: strings of overlapped letter fragments and strings of random letters presented in nonvertical orientations (tilted). With the exception of associated words, masking effectiveness increased directly with the similarity of the mask to the class of target items, words. Jacobson found little masking by visual noise, letter fragments, and tilted letters, although masking increased gradually across the three. Strong masking effects were found for randomly selected letters and unassociated words. These results suggest that words are only weakly masked by "unwordlike" masks, such as visual noise, letter fragments, and even tilted letters, but are strongly affected by "wordlike" masks, even randomly selected upright letters.

The one peculiar finding in Jacobson's $(1973,1974)$ studies is the extremely weak masking effect of one word upon another when the two have high associative strength. Jacobson reported evidence that this effect could not be due to a strategy of simply guessing words associated with the clearly seen mask; however, the implications of Jacobson's results are unclear. Allport (1977) also reported evidence that semantic aspects of a word are available to an observer even when the identity of the word is effectively masked. Unfortunately, Allport's study is seriously flawed. Evidence was presented that subjects sometimes report words semantically, but not graphemically or phonemically, related to a masked word; however, no attempt was made to show that these results were different from what might be expected by chance. In any case, the influence of semantic relatedness in masking, apart from structural relatedness, deserves further study.

The intent of this experiment was to replicate and extend the findings of the disparate studies that have been reviewed. Following Johnston and McClelland (1973), it was predicted that masking for all target types would be equivalent with a blank mask, but that words would experience significantly less masking than would letters when masked by overlapped letter strings. Following Turvey (1973), the masking functions for the blank mask should follow the multiplicative rule, whereas letters masked by overlapped letter strings should primarily follow the linear rule. Following Jacobson (1973, 1974), words should only be significantly masked by words and pseudowords. The unique contributions of this experiment were the inclusion of pseudowords as targets and masks, the masking of letters by words, and the ability to determine the functional masking rule for each target-mask combination. Specific questions of interest were the locus of masking effects as deduced from the masking functions and the role of target-mask similarity. The presence of the word-letter effect in the Reicher (1969) task with an "unwordlike" mask and Jacobson's finding of strong masking of words only by "wordlike" masks suggest that the the word-letter effect might become a significant letter-word effect with a wordlike mask. This hypothesis, that masking effectiveness depends on the orthographic similarity of target and mask, was tested.

\section{METHOD}

\section{Subjects}

The subjects were the authors, who alternately served as experimenter and subject. Both subjects were native English speakers, had normal vision, were well experienced with tachistoscopic viewing, and were familiar with the stimulus materials. It was felt that this familiarity would minimize the effects of 
НАНH

88888 вввев

ММАКМ ВУУУУ

ชระชช

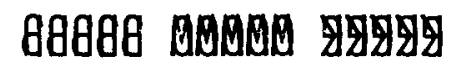

ว व

80600

\section{ZZZZZ 89898}

Figure 1. Overlapped letter-string masks.

practice that have been shown to diminish the effectiveness of a pattern mask, while having little or no effect on masking by blank flashes (Schiller, 1965).

\section{Material and Apparatus}

The target stimuli consisted of the 26 letters of the alphabet, 80 high-frequency five-letter words, and 80 pronounceable pseudowords. The stimuli used as masks included a blank white card, the 160 words and pseudowords, and 24 overlapped letter strings. The words and pseudowords are presented in the Appendix and the overlapped letter strings are presented in Figure 1 in the inverted orientation in which they were used.

All stimuli were typed on $15.2 \times 22.9 \mathrm{~cm}$ white cards, using an IBM Selectric typewriter and uppercase Orator typeface, for presentation in an Iconix three-field tachistoscope. The fiveletter stimuli were $.4 \mathrm{~cm}$ high and $1.2 \mathrm{~cm}$ long, subtending a vertical visual angle of $.25 \mathrm{deg}$ and a horizontal visual angle of $.75 \mathrm{deg}$ when viewed in the tachistoscope. The single-letter targets were typed in the same position as the middle letter in the five-letter strings. The luminance of the target and mask fields was equated. Luminance was measured to be approximately $1.1 \log \mathrm{fL}$. Measurements were made with a cadmium sulfide type photographic exposure meter, and the measures were converted to $\log$ fL (Coren \& Miller,'1973).

\section{Procedure}

CISIs were determined for each target-mask combination for target durations of $2,3,4,6,8,10,14,18,24$, and 32 msec. The order of the target durations was randomly determined for each subject. CISIs for all target-mask combinations were determined at each target duration before proceeding to the nex target duration. Within each target duration, the order of targetmask combinations was also randomized.

A CISI for each combination of target type, mask type, and target duration was determined over a sequence of trials in the following manner. The subject was informed of the target duration, type of target, and type of mask he would receive in the forthcoming block of trials. On each trial, the subject looked into the tachistoscope and viewed a uniform dark field with four dots of light forming the corners of a fixation rectangle (.94 deg horizontal by .63 deg vertical). After receiving a verbal ready signal from the experimenter, the subject initiated the trial with a handswitch. After $500 \mathrm{msec}$, the target was presented centered in the fixation rectangle for the appropriate target duration. This was followed by a dark ISI and then the mask for 25 msec. A different target-mask stimulus pair was randomly selected for each trial. Initially, the mask immediately followed the target (zero ISI). On all trials, the subject reported the target, guessing if necessary. If the subject was correct, the ISI was kept the same and another trial was presented. If the subject was incorrect, the ISI was increased. On the early trials when the subject was unable even to detect the presence of a target, ISI was incremented by $10 \mathrm{msec}$. Once the target began to be detected, these increments were reduced to $5 \mathrm{msec}$, and then to 2 msec. If the subject misidentified a target after having correctly identified one or more targets, the ISI was increased by only $1 \mathrm{msec}$. When the subject correctly identified four consecutive targets, the ISI was recorded as a CISI. The ISI was then reduced by about $10 \mathrm{msec}$, or to a point at which the subject could no longer correctly report the target. The ISI was then increased in the same way as for the first determination until the subject again identified four consecutive targets. This procedure was repeated for three determinations of CISI for each target-mask combination at each target duration. The subject remained light adapted throughout the experiment by diverting his eyes from the tachistoscope between trials. Data were collected over a 2 -month period, with one or two 1-h sessions daily. Test sessions totaled approximately $40 \mathrm{~h}$ for each subject.

After completing the initial data collection, it was deemed necessary to replicate the determination for the letter and word targets with overlapped letter-string masks because of the large amount of variability encountered in these cells of the design. The procedure was essentially the same with two modifications. First, two faintly visible vertical lines, one above and one below the position at which the single letters were presented, were added to the fixation field. Second, the three measures of CISI for each of the replicated cells were independently determined. That is, a determination was made for each target type by mask type by duration condition prior to collecting the second and third determinations for these conditions. The ordering of the target-type, mask-type, and duration conditions was randomized for each determination for each subject.

\section{RESULTS}

Sums of the three CISI determinations for each subject in all conditions of the design are presented in Table 1 . The replication of the overlapped letters mask condition is presented in Table 2. The experiment consisted of an orthogonal five-factor design with the following factors: the two subjects, the 10 target durations, the three target types, the four mask types, and the three CISI determinations nested within the other four factors. The mean difference between the two subjects $[F(1,480)=1,448.78, p<.001]$ and the effect of target duration $[F(9,9)=27.80, p<.001]$ were both significant.

The main effect of target type was not significant $[F(2,2)=7.01, p<.127]$. Examination of the mean CISI for the different target types revealed that there was virtually no difference between words and pseudowords $(12.9$ vs. $13.3 \mathrm{msec})$, whereas letter targets required a longer CISI $(19 \mathrm{msec})$. There was a significant main effect of mask type $[F(3,3)=436.26, p<.001]$. Multiple comparisons using the Scheffé method indicated that the blank mask was less effective than overlapped letters $[F(3,3)=97.80, p<.001]$ and the overlapped letters were less effective than word and pseudoword masks $[F(3,3)=85.64, p<.002]$. There was no significant difference between word and pseudoword masks $[F(3,3)=2.61, p>.20]$.

There are two possible explanations for the lack of a difference between words and pseudowords. The 
Table 1

CISIs for the Two Subjects at Each Combination of Mask Type Target Type, and Target Duration

\begin{tabular}{|c|c|c|c|c|c|c|c|c|c|c|c|}
\hline \multirow{2}{*}{$\begin{array}{l}\text { Tar- } \\
\text { get }\end{array}$} & \multirow{2}{*}{$\begin{array}{c}\text { Sub- } \\
\text { ject }\end{array}$} & \multicolumn{10}{|c|}{ Target Duration } \\
\hline & & 2 & 3 & 4 & 6 & 8 & 10 & 14 & 18 & 24 & 3 \\
\hline & & \multicolumn{10}{|c|}{ Blank Mask } \\
\hline $\mathbf{L}$ & $\begin{array}{l}\text { G.T. } \\
\text { R.C. }\end{array}$ & $\begin{array}{l}55 \\
71\end{array}$ & $\begin{array}{l}23 \\
64\end{array}$ & $\begin{array}{l}25 \\
50\end{array}$ & $\begin{array}{l}12 \\
33\end{array}$ & $\begin{array}{r}3 \\
18\end{array}$ & $\begin{array}{r}2 \\
32\end{array}$ & 0 & $\begin{array}{l}0 \\
4\end{array}$ & $\begin{array}{l}0 \\
0\end{array}$ & $\begin{array}{l}0 \\
0\end{array}$ \\
\hline PW & $\begin{array}{l}\text { G.T. } \\
\text { R.C. }\end{array}$ & & & $\begin{array}{r}4 \\
49\end{array}$ & $\begin{array}{r}0 \\
32\end{array}$ & $\begin{array}{r}0 \\
13\end{array}$ & $\begin{array}{r}0 \\
12\end{array}$ & & & & 0 \\
\hline \multirow[t]{2}{*}{ W } & $\begin{array}{l}\text { G.T. } \\
\text { R.C. }\end{array}$ & 3 & & $\begin{array}{l}12 \\
41\end{array}$ & $\begin{array}{r}7 \\
28\end{array}$ & $\begin{array}{r}0 \\
15\end{array}$ & $\begin{array}{r}0 \\
17\end{array}$ & 0 & 0 & & 0 \\
\hline & & \multicolumn{10}{|c|}{ Overlapped Letters Mask } \\
\hline $\mathrm{L}$ & $\begin{array}{l}\text { G.T. } \\
\text { R.C. }\end{array}$ & $\begin{array}{l}121 \\
142\end{array}$ & $\begin{array}{r}86 \\
104\end{array}$ & $\begin{array}{l}80 \\
87\end{array}$ & $\begin{array}{l}87 \\
85\end{array}$ & $\begin{array}{l}28 \\
65\end{array}$ & $\begin{array}{r}12 \\
107\end{array}$ & & $\begin{array}{r}9 \\
88\end{array}$ & $\begin{array}{l}5 \\
4\end{array}$ & $\begin{array}{l}0 \\
3\end{array}$ \\
\hline PW & $\begin{array}{l}\text { G.T. } \\
\text { R.C. }\end{array}$ & $\begin{array}{r}75 \\
109\end{array}$ & & $\begin{array}{l}53 \\
58\end{array}$ & $\begin{array}{l}36 \\
48\end{array}$ & $\begin{array}{l}20 \\
30\end{array}$ & $\begin{array}{r}6 \\
30\end{array}$ & $\begin{array}{r}2 \\
19\end{array}$ & $\begin{array}{r}0 \\
10\end{array}$ & $\begin{array}{l}0 \\
0\end{array}$ & 0 \\
\hline W & $\begin{array}{l}\text { G.T. } \\
\text { R.C. }\end{array}$ & $\begin{array}{r}89 \\
102\end{array}$ & $\begin{array}{l}60 \\
79\end{array}$ & $\begin{array}{l}38 \\
61\end{array}$ & $\begin{array}{l}39 \\
49\end{array}$ & $\begin{array}{l}18 \\
34\end{array}$ & $\begin{array}{r}9 \\
36\end{array}$ & $\begin{array}{r}6 \\
13\end{array}$ & $\begin{array}{r}1 \\
12\end{array}$ & $\begin{array}{l}0 \\
0\end{array}$ & 0 \\
\hline & & \multicolumn{10}{|c|}{ Pseudoword Mask } \\
\hline $\mathbf{L}$ & $\begin{array}{l}\text { G.T. } \\
\text { R.C. }\end{array}$ & $\begin{array}{l}120 \\
133\end{array}$ & $\begin{array}{r}96 \\
129\end{array}$ & $\begin{array}{l}106 \\
109\end{array}$ & $\begin{array}{l}105 \\
105\end{array}$ & $\begin{array}{r}69 \\
89\end{array}$ & $\begin{array}{r}42 \\
114\end{array}$ & $\begin{array}{l}23 \\
72\end{array}$ & $\begin{array}{r}2 \\
106\end{array}$ & $\begin{array}{r}4 \\
61\end{array}$ & 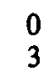 \\
\hline W & $\begin{array}{l}\text { G.T. } \\
\text { R.C. }\end{array}$ & $\begin{array}{l}120 \\
118\end{array}$ & $\begin{array}{l}107 \\
104\end{array}$ & $\begin{array}{l}83 \\
83\end{array}$ & $\begin{array}{l}82 \\
87\end{array}$ & $\begin{array}{l}60 \\
59\end{array}$ & $\begin{array}{l}34 \\
63\end{array}$ & $\begin{array}{l}22 \\
43\end{array}$ & $\begin{array}{r}3 \\
54\end{array}$ & $\begin{array}{r}0 \\
35\end{array}$ & 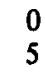 \\
\hline W & $\begin{array}{l}\text { G.T. } \\
\text { R.C. }\end{array}$ & $\begin{array}{l}116 \\
122\end{array}$ & $\begin{array}{l}93 \\
89\end{array}$ & $\begin{array}{l}80 \\
78\end{array}$ & $\begin{array}{l}72 \\
80\end{array}$ & $\begin{array}{l}62 \\
61\end{array}$ & $\begin{array}{l}27 \\
70\end{array}$ & $\begin{array}{l}35 \\
38\end{array}$ & $\begin{array}{l}28 \\
63\end{array}$ & $\begin{array}{r}4 \\
33\end{array}$ & 0 \\
\hline & & \multicolumn{10}{|c|}{ Word Mask } \\
\hline $\mathbf{L}$ & $\begin{array}{l}\text { G.T. } \\
\text { R.C. }\end{array}$ & $\begin{array}{l}119 \\
147\end{array}$ & $\begin{array}{r}92 \\
120\end{array}$ & $\begin{array}{r}97 \\
122\end{array}$ & $\begin{array}{r}100 \\
90\end{array}$ & $\begin{array}{l}73 \\
72\end{array}$ & $\begin{array}{r}45 \\
115\end{array}$ & $\begin{array}{l}36 \\
71\end{array}$ & $\begin{array}{l}10 \\
87\end{array}$ & $\begin{array}{r}3 \\
69\end{array}$ & 0 \\
\hline PW & $\begin{array}{l}\text { G.T. } \\
\text { R.C. }\end{array}$ & $\begin{array}{l}108 \\
119\end{array}$ & 92 & 86 & $\begin{array}{l}70 \\
71\end{array}$ & $\begin{array}{l}49 \\
67\end{array}$ & $\begin{array}{l}23 \\
74\end{array}$ & $\begin{array}{l}29 \\
35\end{array}$ & $\begin{array}{r}9 \\
43\end{array}$ & $\begin{array}{r}1 \\
22\end{array}$ & 1 \\
\hline W & $\begin{array}{l}\text { G.T. } \\
\text { R.C. }\end{array}$ & $\begin{array}{l}106 \\
126\end{array}$ & $\begin{array}{l}79 \\
94\end{array}$ & $\begin{array}{l}61 \\
97\end{array}$ & $\begin{array}{l}55 \\
68\end{array}$ & $\begin{array}{l}53 \\
58\end{array}$ & $\begin{array}{l}36 \\
67\end{array}$ & $\begin{array}{l}27 \\
33\end{array}$ & $\begin{array}{r}3 \\
42\end{array}$ & $\begin{array}{r}1 \\
10\end{array}$ & 0 \\
\hline
\end{tabular}

Note-Each value represents the sum of three CISI determinations in milliseconds. $L=$ letter target; $P W=$ pseudoword target; $W=$ word target.

Table 2

Partial Replication of the Overlapped Letter-String Mask Condition

\begin{tabular}{llrrrrrrrrrr}
\hline & & \multicolumn{10}{c}{ Tar- } \\
get & $\begin{array}{l}\text { Sub- } \\
\text { ject }\end{array}$ & 2 & \multicolumn{1}{c}{3} & 4 & 6 & 8 & 10 & 14 & 18 & 24 & 32 \\
\hline \multirow{2}{*}{ Letter } & G.T. & 105 & 98 & 64 & 50 & 34 & 30 & 17 & 1 & 2 & 0 \\
& R.C. & 126 & 125 & 110 & 88 & 87 & 69 & 70 & 56 & 22 & 7 \\
\multirow{3}{*}{ Word } & G.T. & 82 & 56 & 51 & 34 & 14 & 10 & 0 & 0 & 0 & 0 \\
& R.C. & 113 & 82 & 81 & 60 & 36 & 36 & 16 & 8 & 1 & 0 \\
\hline
\end{tabular}

Note-Each value represents the sum of three CISIs in milliseconds.

subjects were very familiar with the pseudowords because of the large amount of experience that they had with them. Therefore, the pseudowords might have been effectively treated as words. Second, the pseudowords were orthographically regular and pronounceable, which might minimize or eliminate a word-superiority effect when coupled with extensive practice (see Manelis, 1974). Because of their apparent equivalence, all future comparisons combine words and pseudowords as both targets and masks. The combined word-pseudoword conditions will simply be referred to as "words."

Differences in the masking effectiveness of the four mask types were suggested by the significant interaction of mask type with duration $[\mathrm{F}(27,27)=1.88, \mathrm{p}<.053]$ and the marginally significant interaction of target type with mask type $[F(6,6)=3.34, p<.085]$. These effects can be seen in Figure 2. The masking functions were steepest for the blank mask, and the difference between letter and word targets for this mask was not significant (Scheffe $F<1$ ). For the overlapped letter and word masks, the masking functions were less steep, and letters experienced significantly more masking than words.

It has been suggested that the masking functions relating CISI to target duration will be a composite of linear and multiplicative components. Turvey's (1973) two masking rules are special cases of a general threeterm linear model as follows:

$$
\text { CISI }=\mathrm{L} \times \mathrm{TD}+\mathrm{M} \times(1 / \mathrm{TD})+\mathrm{K},
$$

where TD is target duration, $L$ is the coefficient of the linear component, $\mathrm{M}$ is the coefficient of the multiplicative component, and $\mathrm{K}$ is the correction for the mean of the masking function. Thus, Turvey's linear masking rule is the case where $L=-1$ and $M=0$, and the multiplicative masking rule is the case where $\mathrm{L}=0, \mathrm{~K}=0$, and $T D \neq 0$. Equation 1 was fit to the data by multiple regression. The replication of the overlapped letters mask was pooled with the original determinations, as were words and pseudowords as targets and masks for these fits. The obtained parameter values, multiple Rs, and standard errors are listed in Table 3 . The regression equations are plotted as the smooth curves in Figure 2.

The composite functions provide extremely good fits. The implications of the parameter estimates can best be understood by first examining the letter-blank target-mask condition and the letter-word target-mask condition. the letter-blank condition is almost a pure multiplicative relation, in that $\mathrm{L}$ and $\mathrm{K}$ are effectively equal to zero. Likewise, the letter-word condition most nearly approximates a pure linear relation. The $\mathrm{L}$ parameter is almost equal to -1 and the $M$ parameter is the smallest of any of the six $M$ values. The fact that all six functions have nonzero multiplicative components is to be expected, because the presentation was binocular. Hence, the short target durations experienced considerable peripheral masking (Turvey, 1973). All the remaining curve fits may be understood in relation to these two. The letter/overlapped letter condition possessed strong linear masking effects. $L$ approached -1 and $\mathrm{K}$ was much greater than zero. Words demonstrated primarily multiplicative rule masking under both the blank mask and the overlapped letters mask. Only the word-word condition began to show a strong linear component, and then only to the level found for letters under overlapped letter masking.

\section{DISCUSSION}

The cells of the present design that were replications 


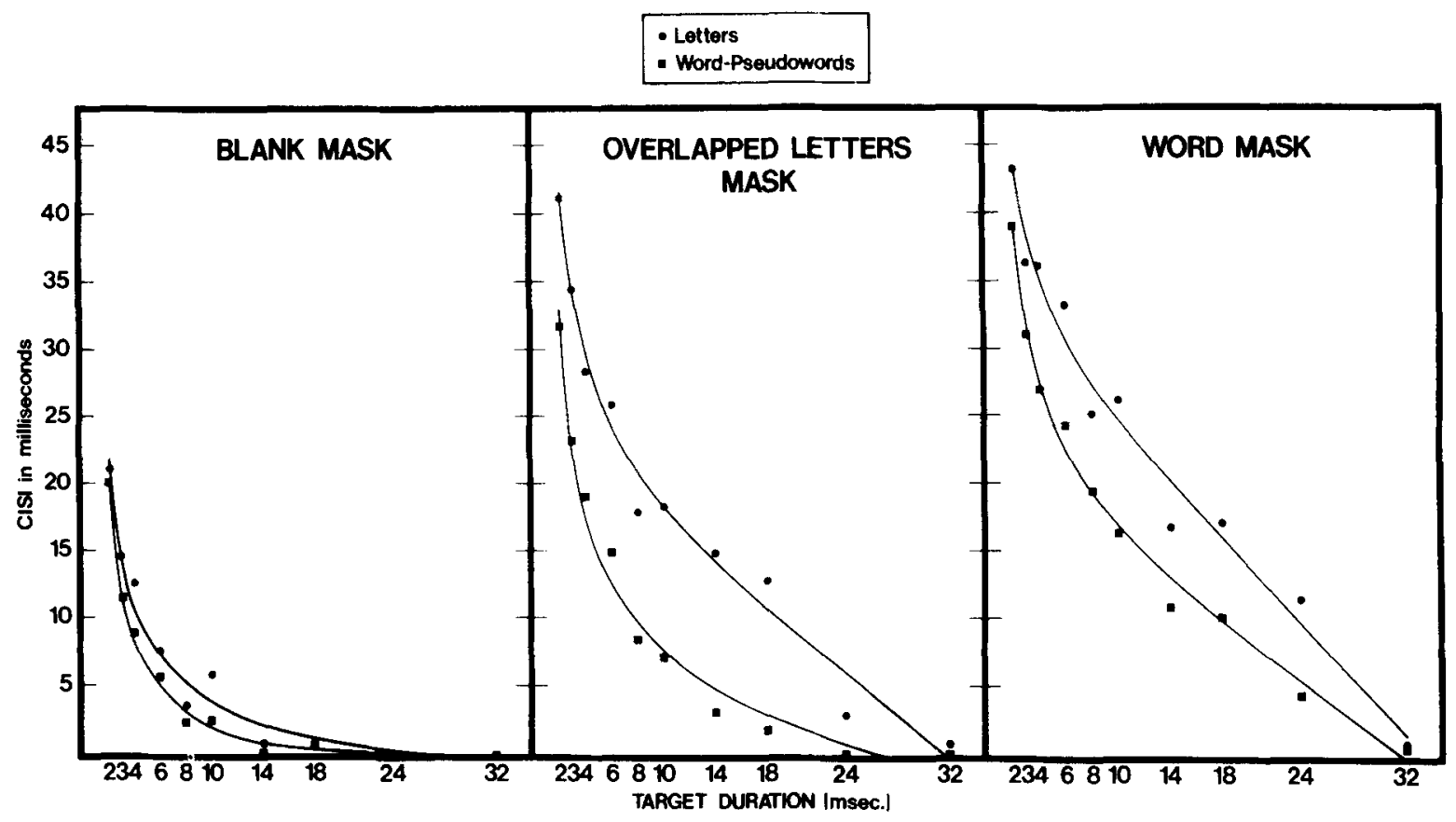

Figure 2. CISIs for word and letter targets plotted separately for each mask type as a function of target duration. Smooth curves represent best-fitting theoretical masking functions.

of previous studies produced the expected results. Words and letters demonstrated equivalent performance with a blank mask, but words suffered less masking than letters when masked by overlapped letters (Johnston \& McClelland, 1973). Words were only effectively masked by wordlike masks (Jacobson, 1973, 1974). The masking functions for letters masked by blank flash and overlapped letters had the same form as observed by Turvey (1973).

Utilizing the logic of Turvey's (1973) distinction between peripheral and central masking, the masking functions may be categorized as follows. Both letters and words experienced peripheral masking when masked with a blank flash. The masking functions for letters masked by overlapped letters and by words were dominated by central masking. However, words masked by overlapped letters experienced primarily peripheral masking. Central masking became evident for words when masked by words.

The two major contemporary theories of backward masking are those of Turvey (1973), reviewed earlier, and of Breitmeyer and Ganz (1976). Breitmeyer and Ganz's theory is directly tied to physiological data that the visual system analyzes its input by performing a twodimensional Fourier analysis on the visual scene, and that Fourier spectral bands possess different extraction latencies. Backward masking is the interference on the more slowly extracted medium to high spatial frequency information from the target by the rapidly extracted low spatial frequency information from the mask. In the most recent statement of Turvey's theory, Michaels and Turvey (Note 1) have proposed three loci for masking. The first is peripheral integration, the second is central integration, which they identify with the interchannel interference of Breitmeyer and Ganz, and the third is central interruption or replacement.

Before endeavoring to use these theories to suggest precise theoretical loci for the masking effects we have observed, a study by Hellige, Walsh, Lawrence, and Prasse (in press) must be discussed. Hellige et al. were interested in the influence of figural relationships between target and mask on masking. They examined masking functions for the letters $\mathrm{C}, \mathrm{O}, \mathrm{Q}, \mathrm{S}, \mathrm{E}, \mathrm{I}, \mathrm{L}$, and $T$ when masked by an overlapped composite of the four curved letters or an overlapped composite of the four angular letters. They were interested in determining the masking functions when target and mask completely overlapped (e.g., curved letter with curved letter composite or vice versa) and when it did not (e.g., curved letter with angular letter composite or vice versa). They reasoned that if integration masking was synonymous with luminance summation, then masking would be less pronounced for the completely overlapping target-mask case. This would result from a summation of dark areas for the target letter and mask that would permit relatively unimpaired discrimination of the target

Table 3

Parameter Estimates for the Linear and Multiplicative Components of the Masking Functions

\begin{tabular}{llrrrrr}
\hline $\begin{array}{c}\text { Mask } \\
\text { Type }\end{array}$ & $\begin{array}{l}\text { Target } \\
\text { Type }\end{array}$ & L & M & K & R & SE \\
\hline \multirow{2}{*}{ Blank } & Letter & -.08 & 42.98 & .38 & .986 & 1.38 \\
& Word & .05 & 45.61 & -3.15 & .996 & .64 \\
Overlapped & Letter & -.69 & 44.81 & 20.60 & .990 & 2.02 \\
Letters & Word & -.22 & 59.49 & 3.65 & .991 & 1.65 \\
& Letter & -.99 & 25.52 & 32.42 & .989 & 2.25 \\
Words & Word & -.64 & 43.20 & 18.91 & .996 & 1.27 \\
\hline
\end{tabular}


letter. Hellige et al. reasoned that if holistic interruption or iconic replacement were the source of masking, then masking should not differ between the completely overlapping and the incompletely overlapping targetmask conditions. Hellige et al. found that for backwardmasking stimulus onset asynchronies (SOAs) of 0 to $20 \mathrm{msec}$, masking was significantly less pronounced for the completely overlapping mask. This was interpreted as evidence for luminance summation as the source of masking in this region of the masking function. Beyond 20 -msec SOA, they found that the completely overlapped target-mask condition was more effective than the incompletely overlapped target mask. They indicated that this masking effect is consistent with a featurespecific or spatial frequency interference explanation, such as that of Breitmeyer and Ganz (1976), but not with holistic interruption. The Hellige et al. results are also consistent with the Michaels and Turvey (Note 1) central integration masking.

The peripheral masking (multiplicative component) found in the present experiment was almost certainly due to luminance summation. The temporal parameters were correct for this type of masking (Hellige et al., in press; Turvey, 1973). The central masking (linear component) may have been either central integration or central interruption. The Hellige et al. results suggest that our central masking was primarily central integration. Phenomenally, we experienced the impression of a target-mask montage more frequently for letters than for words. Our phenomenal impression for the word-word conditions was consistent with Turvey's (1973) reports of central interruption. There was the feeling that the target was seen clearly but, on the threshold of identification, it was snatched away by the intruding mask. Thus, we would from our phenomenal impression identify the central masking of letters with central integration masking and the central masking of words with central interruption masking, even though the masking functions are insufficient to distinguish the two central loci.

A hypothesis was advanced that categorical or orthographic similarity between the target and mask might be the primary determinant of masking effectiveness. This was predicated on the assumption that letters and overlapped letter strings are treated more similarly, perhaps more as geometric than as orthographic forms, than are words and overlapped letter strings. This leads to the prediction that the masking function for words lies below the function for letters with overlapped letter-string masks, but that the masking function for letters lies below the function for words with the wordlike masks. This prediction was clearly disconfirmed. This rejection of the strong target-mask similarity hypothesis renders theories of masking based on categorical similarity less tenable.

Although orthographic similarity between target and mask was not the primary determinant of masking effectiveness, the fact remains that overlapped letter strings differed from wordlike strings in overall masking effectiveness and, particularly, in the ability to centrally mask letters and words. The precise source of these differences cannot be determined from the present data. The two classes of masks share many physical similarities. Both appeared as a string of five "characters." The overlapped letter strings contained letterlike features, although perhaps at somewhat greater density than the word and pseudoword strings. The words and pseudowords were orthographically regular, although Jacobson's $(1973,1974)$ report of strong masking by random letter strings suggests that orthographic regularity may not be a necessary condition. Further research is needed to demonstrate precisely what determines masking effectiveness.

In summary, words and letters experienced differential amounts of masking when masked by a blank flash, overlapped letters, or words. Neglect of this factor in word recognition research has serious implications for theories of word recognition. Theories that suggest special visual status or special processing advantages for words must indicate how these advantages permit words to evade central masking when single letters cannot. In a recent paper, Massaro and Klitzke (Note 2) proposed such a model. Four-letter words, four-letter nonwords, and single letters were masked by overlapped letter fragments followed by a two-alternative forced choice for one of the letters in the display. The SOA between stimulus display and mask was varied from 38 to $203 \mathrm{msec}$. There was also a no-mask condition, in which only the display and choices were presented. This procedure permitted the tracing of masking functions for words, nonwords, and letters. A measure of discriminability, $\mathrm{d}^{\prime}$, was plotted against target-mask SOA. Discriminability of the correct alternative rose from chance at the shortest masking interval to asymptotic discriminability in the no-mask condition. This asymptote was higher for letters than for either words or nonwords, a result attributed to the lateral masking effects of the three neighbor letters on the critical letter. Thus, letters alone were more discriminable than the individual letters in words under comparable viewing conditions without a mask. The masking function for words rose more quickly than either the function for single letters or the function for nonwords. Massaro and Klitzke attributed this result to a faster rate of visual processing for words due to the orthographic regularities they possess. The strength of this formulation was demonstrated by a quantification of these two ideas. By identifying the masking functions as negatively accelerated discriminability growth curves, the rate of visual processing as the rate parameter of the growth function, the final level of discriminability as the asymptote parameter of the function, and the stimulusmask SOA as a measure of the time available to process the visual information (which assumes that masking interrupts processing), Massaro and Klitzke provided quite good accounts of their data. Most impressive was the fit for the nonword data. They assumed that nonwords have the same asymptote as words, thus 
assuming that lateral masking is equivalent for word and nonword strings. They assumed that nonwords have the same growth rate as single letters because they do not possess facilitating orthographic structure. With these assumptions, the fit was excellent.

The results of the present experiment are consistent with the process account of Massaro and Klitzke (Note 2). Although the whole-report threshold technique used here gives an overall advantage to words due to the greater information present in five letters than in one, letters and words showed comparable performance in the blank mask condition. In Massaro and Klitzke's terms, asymptotic discrimination of words and letters was equivalent. The processing rate was greater for words than for letters when masked with overlapped letters (similar to their letter fragments). This can be inferred from the fact that central masking was successfully avoided by words. This would result from the features of the target display being extracted and organized to an unmaskable representation before the mask had its disrupting effects, whereas the slower extraction and organization of a single letter's features permit central disruption.

However, Massaro and Klitzke's (Note 2) formulation is inadequate. It was predicated on the assumption that masking terminates processing through interruption. This interruption assumption is certainly questionable (Hellige et al., in press; Michaels \& Turvey, Note 1). There is also nothing in their formulation that would predict that word masks would produce different masking functions than would overlapped letter strings. Nevertheless, the approach of Massaro and Klitzke serves as a paradigm for understanding the relation between masking variables; understanding that is clearly needed.

\section{REFERENCE NOTES}

1. Michaels, C. F., \& Turvey, M. T. Central sources of visual masking: Indexing structures supporting seeing at a single brief glance. Manuscript submitted for publication, 1978.

2. Massaro, D. W., \& Klitzke, D. The role of lateral masking and orthographic regularity in letter and word recognition. Manuscript submitted for publication, 1978.

\section{REFERENCES}

AllPoRT, D. A. On knowing the meaning of words we are un. able to report: The effects of visual masking. In S. Dornic (Ed.), Attention and performance VI. Hillsdale, N.J: Erlbaum, 1977.

Breitmeyer, B. G., \& Ganz, L. Implications of sustained and transient channels for theories of visual pattern masking, saccadic suppression, and information processing. Psychological Review, 1976, 83, 1-36.

CoRen, S., \& Miller, J. The use of photographic exposure meters as photometers. Behavior Research Methods \& Instrumentation, 1973, 5, 357-360.

ErIKsEN, C. W. Temporal luminance summation effects in backward and forward masking. Perception \& Psychophysics, 1966, 1, 87-92.

Hellige, J. B., Walsh, D. A., Lawrence, V. W., \& Prasse,
M. Figural relationship effects and mechanisms of visual masking. Journal of Experimental Psychology: Human Performance and Perception, in press.

JACOBSON, J. Z. Effects of association upon masking and reading latency. Canadian Journal of Psychology, 1973, 27, 58-69.

JACOBSON, J. Z. Interaction of similarity to words of visual masks and targets. Journal of Experimental Psychology, 1974, 102, 431-434.

Johnston, J. C., \& McClelland, J. L. Visual factors in word perception. Perception \& Psychophysics, 1973, 14, 365-370.

Juola, J. F., LeavitT, D. D., \& ChoE, C. S. Letter identification in word, nonword, and single-letter displays. Bulletin of the Psychonomic Society, 1974, 4, 278-280.

KahNEMAN, D. Methods, findings and theory in studies of visual masking. Psychological Bulletin, 1968, 70, 404-425.

KuCERA, H., \& Francis, W. N. Computational analysis of present-day American English. Providence, R.I: Brown University Press, 1967.

MANELIS, L. The effect of meaningfulness in tachistoscopic word perception. Perception \& Psychophysics, 1974, 16, 182-192.

Reicher, G. M. Perceptual recognition as a function of meaningfulness of stimulus materials. Journal of Experimental Psychology, 1969, 81, 275-280.

SCHILler, P. H. Monoptic and dichoptic visual masking by patterns and flashes. Journal of Experimental Psychology, 1965, 69, 193-199.

TURVEY, M. T. On peripheral and central processes in vision: Inferences from an information-processing analysis of masking with patterned stimuli. Psychological Review, $1973,80,1-52$.

Appendix

Word (W) and Pseudoword (PW) Stimulus Sets

\begin{tabular}{llllll}
\hline W & PW & W & PW & W & PW \\
\hline close & slose & woman & wiman & never & nevar \\
today & doday & words & wirds & music & musoc \\
short & chort & until & urtil & going & goieg \\
often & eften & areas & aleas & given & givan \\
water & rater & field & faeld & above & abore \\
times & nimes & whose & whese & large & larse \\
front & vront & think & thonk & total & totel \\
shall & chall & death & deith & party & pardy \\
great & sreat & hands & hamds & white & whime \\
group & sroup & child & chuld & force & forse \\
place & klace & south & soyth & three & thret \\
means & teans & voice & voyce & since & sinca \\
power & kower & board & boerd & clear & cleaf \\
leave & meave & while & whyle & under & undew \\
right & dight & every & evary & human & humat \\
major & wajor & began & besan & whole & whola \\
house & hause & later & lamer & young & youns \\
among & atong & class & cless & quite & quita \\
least & loast & along & aleng & court & courn \\
point & peint & being & beong & light & lighe \\
local & lical & asked & asped & small & smalt \\
again & asain & known & knoon & sound & sount \\
level & lavel & found & fourd & study & studi \\
might & myght & seems & seets & early & earli \\
heard & hiard & order & ordur & money & moner \\
sense & sanse & taken & takan & stood & stoot \\
north & narth & thing & thieg & & \\
\hline & & & & & \\
\hline
\end{tabular}

Note-Mean word frequency $=345 /$ million (Kučra \& Francis, 1967).

(Revision accepted for publication September 12, 1978.) 